\title{
Tradiciones Cerámicas de las Altiplanicies de Cundinamarca y Boyacá
}

SILVIA M. BROADBENT 
INDICE DE ANEXOS

Anexo I Ubaté: patio de don Inocencio Conejo

Anexo II Tausa: patio de doña Leonidas Venegas

Anexo III Santander: formas de vasijas

Anexo IV Chiquinquirá: patio de don Benjamín Forero

Anexo V Ráquira: Formas de vasijas

Anexo VI Ubaté: formas de vasijas
Pág. No.

243

244

245

246

247

248 
Cuando se piensa en la cerámica artesanal del altiplano Cundiboyacense, automáticamente surge el nombre de un solo lugar: Ráquira, el famoso "pueblo de lo olleros" desde la época de la Conquista y aún antes. En Bogotá, en los almacenes de "artículos típicos", si el cliente curioso pregunta por el origen de las figuritas de barro cocido, los candeleros, las materas, los pesebres ingenuos con el gallo del mism tamaño que los Reyes Magos, todo esmaltado de color verde, casi siempre le contestan que todo viene de Ráquira. Igualmente, en los mercados pueblerinos, si uno averigua en los puestos donde venden la cerámica tradicional, la respuesta es la misma. Inclusive, he oído "és puro de Ráquira", como orgulloso testimonio a la alta calidad de las or Se recibe la impresión que Ráquira es el único lugar conocido en las tierras frías y templadas de la antigua zona Chibcha donde la cerámica no comercial se fabrica hoy en día. Pero en mis excursiones por la zona, de vez en cuando oí hablar de algunos otros lugares donde hacen cosas de barro. Además, a pesar de su fama general y la cantidad casi increíble de productos cerámicos hechos en el pequeño pero laborioso pueblo de Ráquira, no podía encontrar en la literatura muchos datos detallados sobre los métodos de fabricación, sus características estilísticas específicas, la distribución de sus productos, etc. Como me pareció que tal información seria interesante para compararla con lo que yo estaba tratando de establecer sobre la cerámica prehispánica de la misma zona, en los últimos dos años he emprendido ceramica prehispanica de cerámica campesin algunos vajes chibchas. Y aunque sé que hay otros que tienen moderna del antiguo territorio de los Chibchas. Y aunque se que háa la pena reunir lo más datos de los que yo he podido recoger, me pareció que valdría la pena reunir lo que tenía para darlo a conocer y sacar las conclusiones posibles del material. Con la que tenia para que muy pronto aparezcan informaciones más de fondo por parte de otros investigadores, presento el siguiente informe de mis viajes.

El primer lugar que visité con tal propósito fue Ubaté, donde hace varios años me dijeron en el mercado que ciertas ollas grandes se hacían en una vereda del mismo municipio. Con la amable ayuda del Sr. Alfredo Bernal, secretario de la Alcaldía, en municipio. Cenámica en la vereda Suagá: don Inocencio breve encontré una familia que hace cerámica en la vereda Suaga: don Inocencio Conejo y su señora, quienes viven junto a la escuela veredal, a por lo menos una hora y media de camino del pueblo. Estaban trabajando cuando yo les visité, y como todos los conocer en estos viajes, me recibieron con suma cortesía; entendieron perfecta e instantáneamente lo que yo quería, me mostraron y me explicaron muy claramente lo que hacían, cómo y por qué, $\mathrm{y}$ en breve cooperaron en la manera más cabal con mis investigaciones. Ellos fabrican vasijas de cormas básicas, (a) ollas o tinajas de forma ovoide varios tamaños, mayormente de dos formas básicas, (a) ollas o tinajas de forma ovoide,
de boca abierta, sin cuello, con tres asas verticales, y (b) "pailas" o cuencos de formı 226 semejante a los tradicionales recipientes de cobre del mismo nombre, pero algo más hondos en relación con su diámetro, con dos asas horizontales cerca al borde. Una olla grande de $60 \mathrm{~cm}$. de alto vale 50 pesos; fabrican unas 6 de éstas en la semana, y 10 de tamaño mediano. Una paila de $35 \mathrm{~cm}$. de diámetro y $18 \mathrm{~cm}$. de alto vale 5 pesos. No se dedican exclusivamente a la alfarería, sino que la hacen en los ratos libres de las faenas agrícolas. La mayor parte de su producción la vende personalmente el Sr. Conejo en el mercado de los viernes en Ubaté.

Fabrican sus vasijas por el sistema "coil", sin emplear la rueda o torno de alfarero. Buscan cierta calidad de arcilla, que debe estar limpia de piedras y otras inclusiones (la que estaban trabajando era de color gris oscuro, de textura bastante fina). Se la deja secar, y se muele batiendo los terrones con una macana de madera, o empleando piedra y mano de moler. Se le agrega agua y deja mojar hasta volverse plástica. Cuando está lista se mezcla con arena de río; ésto es lo único que ellos emplean como desgrasante. $\mathrm{La}$ que estaban usando era de partículas lenticulares, algo gruesas, muchas de alrededor de $5 \mathrm{~mm}$. en diámetro o aún más grandes, de color gris oscuro. Cuando le pregunté por qué le agregan arena a la greda, el Sr. Conejo me contestó que era para que las ollas "no toteen" en el fuego.

La mezcla se hace amasándola como masa de pan sobre una plataforma de piedras planas, pero a veces se emplean los pies tanto como las manos para este trabajo. Preparan una cantidad bastante grande de arcilla a la vez; noté un montón de volumen de como un cuarto de metro cúbico dejado sobre una piel de vaca. Para empezar una olla, don Inocencio tomó unos $200 \mathrm{cc}$. de greda así preparada, y formó un óvulo, de cual apretó una concavidad central con el dedo pulgar. Tornando la copa tosca así formada sobre la palma de la mano izquierda, empezó adelgazando las paredes con la otra mano. Entonces, colocó el cuenquito encima de un plinto de piedra de unos 40 $\mathrm{cm}$. de alto, y tomando otro pedazo de arcilla formó con ello un cilindro de unos 2 o $3 \mathrm{~cm}$. de diámetro por unos 25 o $30 \mathrm{~cm}$. de largo que luego sobrepuso al borde de pequeño cuenco ya formado, apretándolo para pegarlo bien. Siguió haciendo subir las paredes de la vasija agregando "salchichas" de arcilla, cada cual apretada a la inferior, trabajando con las manos mojadas; el agua parece facilitar la fusión. La construcción sigue no tanto en forma espiral sino más bien por capas o niveles circulares. La vasija no fue movida durante este proceso; el ceramista dio vueltas caminando alrededor de plinto, agregando cilindro tras cilindro de greda para aumentar la altura de la vasija. Después de llegar al tamaño deseado, siguieron los procesos de adelgazar las paredes, regularizar la forma, alisar, cimentar y dar firmeza a las coyunturas entre los cilfndros de arcilla que forman las paredes, y dar una superficie continua y más o menos lisa. Todo eso se hace con las manos, batiendo con la palma desde afuera contra la otra mano por dentro, o empleando un tiesto o un pedazo de totuma de superficie redondeada contra la parte interna de la pared. Parece que después de formarse al tamaño deseado, pero antes de perfeccionar la forma final, se deja secar por algún tiempo; había dos o tres ollas grandes en este estado durante mi visita, encima de la plataforma de quema.

Después de terminar el acabado final de sus formas y superficie, las vasijas se dejan secar al aire varios días. Antes de someterlas al fuego para cocinarse, se hace un fuego preliminar de hojas secas de frailejón sobre las vasijas, según parece para asegurar que estén bien secas. Después de eso, se queman en un fuego abierto de madera y carbón sobre una plataforma baja al fondo del patio, manteniendo la fogata dos días encendida. Entre las cenizas, sobre la plataforma, noté algunos fragmentos que parecían 
esparto, y había cenizas de esparto adentro de unas ollas que compré, suficiente para hacerme pensar que ésta gramínea formaría un elemento importante del combustible. La única ornamentación que don Inocencio y su señora aplican a su cerámica es con pintura de un mineral rojo, que se muele muy fino sobre una piedra de moler. Se mezcla con agua, y se aplica con un trapo. Los diseños son sencillos, formados por bandas de varios centímetros de ancho: siempre una banda en el borde de la vasija; dos bandas diamétricas en forma de cruz en el interior de una paila y algunas verticales sobre su exterior; hemicírculos pendientes del borde en el exterior de una olla. Aunque son muy sencillos y algo toscos, es claro que los dibujos se aplican a propósito y según algunas normas preconcebidas, no accidental o espontáneamente. A las ollas, según parece, se les da un baño o slip de color anaranjado, pero no se emplea algún esmalte o envidriado. Las superficies externas de las vasijas tienen algo de la característica de "desgrasante arrastrado" de Ráquira (descrito más adelante), pero no llegan a la misma textura. Por sus formas y superficie esta cerámica es fácilmente distinguible de la de Ráquira, y en los tiestos rotos se ve que la pasta también es distinta, especialmente en cuanto al desgrasante. La pasta logra una oxidación completa, y sale de color rosado cremoso. Me dijeron que en la misma vereda de Suagá hay otra familia más que hace cerámica, y que ellos y los Conejo son los únicos en el municipio.

En Ubaté me informaron que también hacen cerámica en la vereda Pajarito del cercano municipio de Tausa. Fui allá, y encontré que hay varias familias de alfareros, de apellidos Vanegas, Gómez, y Forero; tanto hombres como mujeres trabajan en la cerámica. Hacen materas y sus platillos correspondientes, de gran variedad de tamaños, para vender en Zipaquirá y en los mercados de Bogotá, por ejemplo en la Plaza de España y en el Pasaje Rivas. Un señor viejo me dijo que también hace "juguetes", es decir figuritas, pesebres y alcancías, pero solamente a pedidos especiales. Por lo general, se dedican exclusivamente a las materas. Estas se fabrican por medio del torno de alfarero; no se le agrega ningún desgrasante a la arcilla; se le aplica un vidriado a base de plomo; y las cocinan en horno. En varios aspectos culturalmente importantes, entonces, la industria cerámica de Tausa difiere a la de Ubaté, siendo más de tradición europea que indígena.

La arcilla se consigue de pozos en los cerros de la vereda. Según parece, extraen la greda de distintos pozos, de calidades variadas. La que tenía la familia de doña Mercedes Forero de Forero era de color gris claro, mientras la que estaba empleando doña Leónidas Vanegas era más amarillenta. Ambas eran muy plásticas y de textur bastante fina. Es de notarse que se trabaja sobre el torno en una condición mucho más húmeda que la que usa el Sr. Conejo. Unicamente le agregan agua a la arcilla. Doña Leónidas trabaja de la manera siguiente. Una ayudante le prepara la greda; tomando un pedazo de unos dos litros de volumen, lo amasa y dobla sobre una laja inclinada como las que se usan para lavar ropa o amasar pan. Por fin, forma un cono de unos $35 \mathrm{~cm}$. de largo por 15 o 20 de diámetro al fondo y lo coloca sobre el torno cuando se lo pide la fabricante. El torno consiste en dos ruedas de madera conectadas por un eje vertical; la de abajo es la más grande y pesada, sirviendo de volante. Le imprimen movimiento impulsándola con el pie derecho, estando la ceramista sentada tras la ruedı sobre una tabla que forma parte del marco de palos que sostiene todo el equipo. Le rueda de arriba, mucho más pequeña, es la plataforma donde se elaboran las vasijas. Con el cono de greda colocado sobre el centro exacto de la rueda (punto importante, y no muy fácil de lograr sin mucha práctica), la artesana empieza a trabajar, primero haciendo subir la arcilla en una columna por presión de las manos mojadas, después abriéndola desde arriba para formar el espacio hueco y las paredes inclinadas. Trabaja con las manos no contra la parte más cercana del borde sino al lado opuesto. Plasma una pestaña por debajo del borde en el exterior, la cual a veces se termina ondulada. La forma final de las materas es cónica truncada, abriéndose hacia arriba, las parede ligeramente convexas, la boca más o menos igual de diámetro como la altura de la vasija y la base de aproximadamente la mitad del diámetro de la boca, o a veces menos. Cada cono de greda sirve para sacar dos materas; hecha una de la parte superior, la corta por debajo con un hilo de fique y forma otra matera con la greda que queda. A veces graba unos dibujos incisos ondulados sobre el exterior de las materas. Practica tres huecos al fondo para el drenaje y después las pone a secar, al sol cuando hay o bajo techo durante unos ocho días antes de cocinarlas. Me dijo doña Leónidas, en contestación a una pregunta que no emplea una fogata de hojas para acelerar el secamiento de la cerámica, dejándola secar al aire únicamente.

El envidriado se hace del plomo de viejas baterías para automóviles. Se lo machaca, se mezcla con agua, y se lo aplica en bandas al exterior de la matera, empleando una brocha de pintar. Para lograr un color verde, agregan cobre a la mezcla; el plomo por sí solo da un color amarillo. Las vasijas se cocinan en hornos construídos de ladrillo, de forma de colmena. Me dijeron que hay unos 15 en la vereda. Tienen un compartimento inferior para el fuego, y un nivel más arriba donde se coloca la cerámica a cocinar. En Tausa el combustible que emplean es el carbón mineral, pero me dijeron que se necesita cierta clase especial. Hornean dos días seguidos hasta que la cerámica logra un buen color rojo, lo cual se observa quitando uno de los ladrillos que se emplean para tapar la puerta del horno. Desafortunadamente, no se me ocurrió preguntar si el vidriado se aplica antes de poner la cerámica al horno, o si necesita un segundo proceso de cocción. El color de la pasta después de cocinar es variable entre crema y rojo, probablemente según el color de la arcilla, pero en todo caso completamente oxidado. Doña Leónidas me dijo que recibe de 80 centavos hasta un peso por materas de unos $30 \mathrm{~cm}$. de alto, y que hace de 15 a 20 en un día. Antes de terminar mi visita, tenía unas 25 secándose en su patio, todas hechas el mismo día. Los fabricantes de materas de Pajarito me dijeron que no dependen exclusivamente de su artesanía, sino que lo hacen como suplemento de lo que les rinde la agricultura. Es una zona muy erosionada, al parecer superficialmente por lo menos, muy pobre para la agricultura.

Después de éste sitio fuĩ a Chiquinquirá, por haber oído que allá también hacen cerámica. Primero me llevaron a la casa-fábrica de un Sr. Herrera, en el barrio Santa Bírbara en las afueras de la ciudad, tras la Basílica. Aunque no estaba trabajando ese đía, él me mostró su taller. Según parece, vende mucho a la corporación "Artesanías de Colombia", por lo cual ha sido visitado por muchos turistas extranjeros curiosos de ver donde se hacen las figuritas simpáticas que han' comprado. El fabrica materas ver donde se hacen las figuritas simpáticas que han comprado. El fabrica materas, aemejantes a las de Tausa pero con base más pequeña, tasas y platillos, alcancias, lis Vargas, que desafortudamente se había roto al cocinar. Emplea una rueda, semejante a Vargas, que desafortudamente se habia roto al cocinar. Emplea una rueda, semejante a
li de Tausa; no agrega nada fuera de agua a la arcilla, que consigue cerca al centro uibano; cocina la cerámica en hornos construídos de ladrillos, de proporciones un poco más altas y estrechas que los de Tausa, donde quema leña en vez de carbón mineral; y lace uso del mismo vidriado de plomo de baterías, con cobre para el color verde. Me ilijo que no emplea moldes para hacer sus figuras, pero parece que las caras de las liguras de pesebre se forman con molde y también la figura del Niño. Es posible que se 
trata de una estampa o intaglio más que un molde. La pasta de sus materas sería muy difícil distinguir de la de Tausa. Aunque no emplea desgrasante, me dijo que se necesita para hacer ollas muy grandes para evitar que "se derritan" en el horno y para darles más resistencia.

En el mercado del martes en Chiquinquirá, encontré una familia de la vereda Córdoba que vendía cerámica, tanto de su propia hechura como traída de Ráquira. Más tarde, les visité en su finca, a como una hora de camino sobre un cerro donde todavía subsiste un fragmento muy bello de la selva nativa de la región. Se trata del Sr. Benjamín Forero y su familia. Hacen cerámica al torno, sin desgrasante pero con esmalte de plomo de baterías, cocinado al horno, según el estilo ya familiar de Tausa y del barrio de Santa Bárbara. Hacen tazas, candeleros, jarras, ollas redondeadas con un corto cuello vertical, vasijas miniaturas, ceniceros, y alcancías en forma de armadillo Todo se forma sobre el torno, inclusive las alcancías, que se terminan a mano después. La greda se consigue de un pozo a unos 100 metros de la casa, y es de color gris muy claro; rinde una pasta casi blanca cuando se quema, mientras la arcilla de color amarillo da una pasta colorada, según don Benjamín. El dijo que la calidad de la greda es muy importante: "Es como el azúcar al melcocho, entre más liso mejor." Se la pone en un hueco forrado de piedra, se le agrega agua y se deja mojar. Cuando esté blanda, se puede trabajar. Ninguno de los ceramistas entrevistados me dijo que la arcilla debe "reposar" o "fermentar" algún tiempo antes de usarse, como se ha informado en México; sólo que se ablanda con agua.

Don Benjamín tiene dos tornos que ocupan una enramada con techo de chusque Su hijo estaba trabajando en uno cuando yo llegué, haciendo jarras miniaturas; $m$ \& tarde, don Benjamín ocupó el otro para trabajar con candeleros. Los tornos son de mismo estilo que los de Tausa, con un marco de palos, una rueda grande (de unos 80 $\mathrm{cm}$. de diámetro, y unos 5 de grueso) por debajo para hacerla mover con los pies, y if otra rueda, la de formar la cerámica (de unos $30 \mathrm{~cm}$. de diámetro y $2 \mathrm{~cm}$. de grueso) arriba sobre el mismo eje. Había una punta de metal al fondo del eje, que reposabs sobre una plancha vieja "para que baile la rueda", es decir para facilitar su movimiente libre. En realidad, es sorprendente cómo funciona lisa y ligeramente, revolviends perfectamente, aquella máquina aparentemente $\tan$ tosca. Las jarras miniaturas qu estaba haciendo el hijo, de unos $10 \mathrm{~cm}$. de altura, salían una tras otra del mismc montón de arcilla sobre la rueda. Cuando se había formado una se la cortó por debaj con un hilo, se trasladó a una tabla que reposaba sobre el marco del torno, y empezó formar otra. Don Benjamín estaba agregando manijas a unos candeleros previament formados. Tomó un pedazo de greda, y lo tiró con las manos mojadas hasta formar u listón, del cual cortó con el dedo pulgar una serie de pedazos de unos $10 \mathrm{~cm}$. de large Estos se pegaron como manijas a los candeleros, empezando por fijarlos y alisarlos $d$ borde del recipiente central para la vela, tirando y adelgazando con el índice y pulge mojados, para finalmente pegar y alisar al borde de la base del candelero. Despúb. cuando ya tenía un buen número de candeleros con sus manijas y se habian dejado secar un rato, se puso a hacerles bases anulares por debajo. Sobre el torno, formó con greda un soporte adaptado a la forma de los candeleros, con un hueco para recibir in parte central y un canal para la manija. Colocó un candelero boca abajo sobre est soporte, y con un zuncho cortó el anillo de la base, como trabajando madera en un torno horizontal. Después de hacer varios así, los oreó al sol para secarlos más. Me dijo que los objetos se dejan secar "tres soles" antes de cocinar. En todo, don Benjami" trabajó sin ningún afán, cuidadosamente y con mucha atención a la exactitud, de tal manera que sus productos resultaron muy uniformes.

El sistema de envidriar empleado es el mismo de Tausa. Habían ensayado un vidriado de minio (óxido rojo de plomo) pero no les resultó, no pegaba bien a su arcilla. Una batería les cuesta 20 o 25 pesos. La "tierra" que lleva -es decir, todo el material fuera de plomo en las secciones de la batería- hace variar el color del vidriado. En el patio había como una docena de contenedores vacíos, empleados para muchas cosas: como soporte para las vasijas mientras secan, para guardar arcilla húmeda y agua para mojarse las manos durante el trabajo, como butaca, etc. Las vasijas se cocinan en hornos de ladrillo en forma de colmena; había dos en una enramada un poco arriba del patio de trabajo. El combustible es leña, y no carbón mineral, porque éste hace demasiado hollín, según me dijeron.

Aunque venden personalmente en el mercado local, la mayor parte de su producción se vende a intermediarios, quienes la llevan a Bogotá y otras partes. Aproximadamente un mes después de visitar a los Forero, encontré algunas de sus alcancías en forma de armadillo, imposibles de equivocarse en reconocer, en el mercado del pueblo de Bojacá. En una época, los Forero ensayaron llevar personalmente sus mercancías a vender en Bogotá, pero los costos de transporte les comían sus ganancias y resolvieron vender más comodamente a los intermediarios. En septiembre, cuando yo les visitaba, no habían vendido mucho en varios meses; esperaban recibir más pedidos para la última parte del año, las alcancías se hacían para llenar un pedido. Don Benjamín y su hijo hablaban mucho entre ellos sobre qué querían los compradores, qué clase de objetos se vendían más fácilmente; dijeron que las vasijas miniaturas se vendian muy bien. Fuera de la cerámica, sus ingresos dependen de la agricultura, aunque en las cercanías de la casa el único cultivo a la vista era una media fanegada, o aún menos, de maíz y habas.

El Sr. Forero ha trabajado en la cerámica 40 años. No es oriundo de Chiquinquirá: nació en Chocontá, de donde se trasladó hace 35 años. Todavía tiene parientes en Chocontá, en el lugar llamado "Tierra Negra". Me dijo que ellos también hacen alfarería, en especial materas.

Desde Chiquinquirá fui a Ráquira, en viaje corto pero no muy fácil. Puesto que Ráquira es un pueblo muy pequeño algo apartado de la carretera principal, no tiene buen servicio de buses. Hay directos para Bogotá y Tunja todos los días, saliendo muy de madrugada para llegar temprano a las plazas de mercado, pero entre Chiquinquirá y Ráquira había solamente un busecito muy viejo que hacía un sólo viaje de ida y regreso los días de mercado. El transporte de la cerámica, según parece, se hace más que todo en camión.

Me quedé una sola noche en Ráquira. La señora Yolanda Mora de Jaramillo ha hecho en Ráquira un estudio mucho más amplio que los míos, el cual se espera publicar en breve; llevará más información de la que yo puedo presentar. No obstante, ine parece de algún valor presentar lo que alcancé a aprender, por comparación con los đemás lugares. Tal vez la impresión más interesante que recibí fue la de que en Ráquira no hay una sola industria homogénea de fabricación de cerámica, sino dos grupos de alfareros totalmente distintos: los del centro urbano, y los de las veredas. Los del imieblo hacen cerámica vidriada empleando el torno; los del campo hacen cerámica no vidriada, sin emplear el torno europeo. Las formas que fabrican los dos grupos son completamente diferentes. La industria cerámica del centro es más que todo de inadición europea, mas o menos comercializada con miras a los mercados turísticos y 
de decoración de interiores, es decir un mercado metropolitano y aún internacional. La de las afueras es de tradición más bien indígena, de fabricar vasijas para fines utilitarios, orientada hacía el mercado tradicional de la vida campesina.

En el centro urbano visité tres talleres de cerámica, donde fabrican materas, figuritas, alcancías, ceniceros y objetos de adorno como campanas y lámparas. Emplean greda de distintos colores para conseguir tonos variados después de quemarse. No se le agrega arena u otro desgrasante a la arcilla. Emplean el torno de alfarero, y también el torno horizontal para formar las materas. Para fabricar figuritas, ceniceros, etc., en gran número, hacen uso de moldes de yeso, aunque no con el sistema de "slip casting", o sea moldear con greda líquida, que se emplea industrialmente. Me dijeron que habían ensayado tal sistema y no les resultó, porque su arcilla no formó una capa suficientemente gruesa dentro del molde. En uno de los talleres, una señora vieja estaba formando ceniceros, tornándolos sobre la palma de la mano izquierda. Parecían hechos en torno, aunque en realidad no lo son. Para el esmalte o vidriado, emplean el minio; según parece, las piezas se bañan en una suspensión de minio disuelto en agua, y deben dejarse secar antes de cocinar. A mi parecer, este sistema podría llevar algunos peligros de envenenamiento para los ceramistas, pero no pregunté sobre tal problema. Pregunté si conocían el sistema de envidriar con sal, como se ha empleado en Europa desde la época medioeval. Me contestaron que habían oído del sistema y por lo menos uno de ellos lo había ensayado, pero no resulto, salió muy burbujoso. Estos talleres del pueblo son verdaderas fábricas, instalaciones mucho más comerciales que los lugares antes mencionados. Cada cual tiene varios empleados, en vez de tratarse de un sólo fabricante con sus parientes más cercano. Es obvio que son éstas fábricas las que han recibido mayor influencia de los Cuerpos de Paz y otras entidades. Ultimamente, la corporación de artesanías ha construido un Centro de Artesanías en el pueblo, con el fin de fomentar la cerámica y otros oficios; será interesante saber qué influencias resultan de este esfuerzo.

Por fuera del centro urbano visité unas casas de ceramistas en la vereda Pueblo Viejo; las de las señoras Margarita González, Amparo Casas y Lucila Melo. Unicamente la última esta trabajando cuando yo me hice presente, pero según lo que me dijeron todas trabajaban de la misma manera. La Sra. González ya es de alguna edad, y ha dejado de hacer el trabajo pesado personalmente; por lo general, me dijo, tiene tres "lozeras" trabajando. Es decir, emplea ayundantes. Las demás trabajan solas, o con la ayuda de sus familiares. El género del nombre que doña Margarita empleó para hacer referencia a sus ayudantes sugiere que en general son las mujeres quienes trabajan en la cerámica, pero no averigüe esto a ciencia cierta. A diferencia de los alfareros del pueblo, los de Pueblo Viejo no emplean el torno; agregan arena a la arcilla como desgrasante; $y$ no aplican vidriado a su producto. Cocinan la cerámica en horno, pero me informaron que en otra vereda cocinan "en el suelo", es decir en fuego abierto sin horno. Los productos son lo que, encontrados arqueológicamente, yo había identificado como un tipo y denominado Ráquira Desgrasante Arrastrado (Ráquira Dragged-temper Ware) caracterizado por una pasta dura con desgrasante de arena, y una superficie singular, fácilmente reconocible, con ranuras paralelas producidas al arrastrar partículas del desgrasante en el proceso de alisado. Es decir, la superficie no es lisa sino tiene una textura muy característica. Todo parece indicar que tal textura se hace a propósito, no por incapacidad de alisarla perfectamente. Buscar superficies lisas, hasta pulidas y brillantes, es un valor artístico específico de la cerámica europea después de la Edad Media, influido por la porcelana de China que tanto admiraban y anhelaban imitar lo: 232 europeos. En realidad, no es tan importante hoy en día como valor u objetivo del ceramista artístico moderno: más bien, en el arte contempóraneo, en general, se consideran las superficies texturadas más interesantes que las perfectamente lisas. En vista de eso, me parece que no es necesariamente para tomarse por dado que las "lozeras" de Pueblo Viejo en Ráquira busquen hacer su cerámica lo más lisa posible, y que si no lo logran tiene que ser por falta de suficiente destreza. Cuando uno se adapta a la idea de mirar a la textura no como una falla, sino como algo en sí interesante, las vasijas que hacen en las afueras de Ráquira parecen bastante atractivas. Sus formas son muy satisfactorias estéticamente; tienen mucho carácter e indicios de madurez artística, como suele pasar cuando "la forma sigue la función", como rezaba el lema del grupo del Bauhaus, de los fundadores del diseño moderno. Son formas adaptadas a las necesidades de la vida campesina, para recoger agua de un pozo, para cocinar sobre un fogón de tres piedras, para almacenar el maíz, y por supuesto para fermentar la chicha.

Para devolvernos al asunto de los procesos de fabricación, la arcilla seca se muele, batiendo los terrones con una macana de madera para reducirlos a polvo, y después empleando una piedra de moler y su correspondiente mano. La greda pulverizada se mezcla con agua, y se le agrega arena de la quebrada, para que las vasijas no "toteen" en el horno o sobre el fogón, según me contaron las ceramistas. Se le deja reposar hasta que se vuelve plástica, y entonces está lista para trabajar. La manera de formar vasijas como las poras y las ollas es de mucho interés, como me lo mostró doña Lucila Melo. Su ayudante, otra mujer, amasó cuidadosamente una cantidad de greda preparada, y sobre una tabla cubierta de arena para evitar que se le pegue la arcilla, formó un cono de semejante forma y dimensiones como se usan en Tausa. Pero en este caso el cono no se colocó sobre un torno. Doña Lucila la tomó, y metió su puño izquierdo por todo el axis del cono, tornándolo con la mano derecha hasta formar un cilindro hueco tapado al fondo, o sea una vasija muy tosca de paredes gruesas. Colocó éste sobre una plataforma especial, hecha de cerámica, de forma de un platillo sobre un soporte cilíndrico, la cual sirve de "torno lento" (slow wheel). Esta plataforma descansaba sobre una tablita de madera en el suelo. Con su mano izquierda sobre el borde de la vasija, doña Lucila hizo revolver la vasija y su soporte sobre la tabla. Con la derecha, tomó una piedra ovaloide, de unos $10 \mathrm{~cm}$. de largo, $7 \mathrm{~cm}$. de ancho, y 2 $\mathrm{cm}$. de grueso, la cual empleaba para trabajar la vasija desde adentro, mojándose mano y piedra con frecuencia en una olla de agua a su lado. Así adelgazó las paredes de la vasija y ensanchó su diámetro máximo, dándole su forma convexa, siempre tornándola con la mano izquierda o contra las paredes de la vasija o al borde del platillo. Por supuesto, con tal manera de hacer revolver la vasija no alcanza, ni se acerca a la rapidez de movimiento o R.P.M. del torno verdadero, por lo cual no funciona el movimiento circular para darle forma a la vasija por medio de la fuerza centrífuga, que es la manera de funcionar el torno rápido. Sirve más bien para facilitar el acceso a las paredes por todos lados, mientras que es más por medio de la piedra y la fuerza de las manos que se da forma a la vasija. Es de anotarse que la arcilla se emplea en un estado mucho más duro de lo que se emplea con el torno verdadero, donde se necesita arcilla muy blanda, con mucha agua, para facilitar los efectos de la fuerza centrífuga. No se emplea el sistema "coil": la ceramista empieza, desde un principio, trabajando un pedazo de arcilla suficientemente voluminoso para formar toda la vasija, sin necesidad de agregar más para hacer subir las paredes. Otra cosa notable es que por trabajar con la mano y la piedra mojadas se vuelve líquida la capa superficial de la arcilla, con la ensecuencia de que forma lo que parece. después de terminado, un baño de la misma 
arcilla de la pasta ("self slip"). De tiestos encontrados arqueológicamente, yo creía que debían usar un baño de greda líquida, pero parece que es más bien el resultado de emplear mucha agua en el proceso de formar la vasija. Para formar el borde de la olla trabajó con la piedra contra el borde y dos dedos de la mano derecha adentro y afuera, formándose así entre piedra y dedos, tres lados de una cuadrángulo, para moldear un borde muy angular y no redondeado. Formó y alisó la ranura ancha por debajo del borde, muy característica de las ollas de Ráquira. Para una paila con pico, se formó e pico haciendo un hueco en la pared con el dedo índice, agregando un poco de greda alrededor del hueco y trabajándola con dedo y pulgar para formar el pequeño cilindro que es el pico.

Después de darles una formación inicial a como una docena de vasijas, se las deja secar algún tiempo hasta endurecer un poco, cuando se las vuelve a poner sobre el platillo para trabajar más con la piedra adentro y la mano izquierda por fuera hasta llegar a su forma final; antes, se habían dejado en forma más alta y estrecha de lo que iban a terminar. Se vuelve a formar el borde, de la misma manera que se hizo antes, pero con más cuidado. Para formar una asa, se tomó un pedazo de arcilla y se lo estiró con la mano mojada para formar un cilindro y se le pegó a la superficie de la vasija. Tratándose de la asa vertical de un chorote, se abrió una hendidura en un terminal del cilindro, y coloncando la hendidura sobre el borde del chorote como una pinza, se lo pegó ahí. Entonces con los dedos mojados se estiró más la asa hacía abajo, formando las ranuras características de estas asas y se la oprimió a la vasija por debajo dejando algunos centímetros de sobra. Se lo alisó para reunirlo con la superficie, se cortó lo que sobraba con dedo y pulgar, y se empleó para agregar un poquito más de arcilla entre la parte inferior de la asa y la superficie, reforzando así la unión entre el asa y la pared. Las asas horizontales de las ollas y las pailas se hicieron en forma semejante salvo que se las oprimió primero un terminal contra la pared, y se las estiró formando la curva hacía afuera sobre dos o tres dedos de tal manera que quedaban muy bien adaptadas para agarrarse. Para colocar la segunda asa, pasó la mano sobre la boca de la olla diametralmente desde la primera, localizando así el punto opuesto.

Terminada la forma, las vasijas se ponen a secar más, al sol si es posible. Cuando ya están bastante secas, se raspa el exterior con un zuncho, con un pedazo de totuma o con papel de lija. Es la raspadura la que da la distintiva de pequeñas ranuras paralelas a la superficie. Después, se las aplica la decoración de pintura con un trapo. La pintura se hace por medio de moler cierta clase de piedra llamada "chica", de color rojo oscuro, y mezclarla con agua. Aunque las vasijas parezcan pintadas muy burdamente, tal como en Ubaté, siempre hay ciertas pautas, como una faja de pintura sobre el borde y otra por debajo de la ranura ancha en las ollas y pailas. Cuando están perfectamente secas, las vasijas se cocinan en un horno en forma de colmenar, como los de Tausa, hechos de ladrillo, salvo que en algunos se han empleado unas ollas boca abajo una sobre otra para construír la boca de la cámara superior, donde se coloca la cerámica a quemarse. El combustible es leña, como en el pueblo. No emplean el carbón mineral; me dijeron que había vetas en las cercanías, pero que no estaban explotadas. En el pueblo, me expresaron alguna preocupación por las posibilidades de deforestación a raíz del empleo de leña.

Las alfareras que entrevisté en Pueblo Viejo de Ráquira no aplican ningún esmalte a su cerámica. Tampoco se la pinta después de cocinada con pintura casera como a veces se hace en el pueblo, especialmente a las materas y las alcancías.
En la zona de La Candelaria, dependencia del mismo municipio de Ráquira, hay otro núcleo ceramista. Visité muy brevemente aquella parte, donde vi un taller de cerámica cerca al famoso monasterio de los PP. Agustinianos. Lo poco que allá averigiéé es lo siguiente: no emplean la rueda; la arcilla que emplean parece llevar alguna arena, aunque me dijeron que no la agregan; trabajan mujeres en la fabricación de cerámica; hacen materas, figuritas de pesebre, alcancias en forma de armadillo, y vasijas semejantes a las producidas en las afueras del pueblo de Ráquira.

En el año de 1960, me dijeron en Chocontá que allí hacían "loza verde" en la vereda El Tejar. Por eso, a cierto tipo de cerámica reciente que encontré arqueológicamente en ese municipio lo bauticé Chocontá Vidriado. En efecto, el 15 de octubre de 1960, compré en el mercado de Chocontá una matera con su platillo y otra pareja miniatura de tal cerámica, pagando 85 centavos en total. El vendedor me dijo que se hicieron en la vereda El Tejar. Otra persona me informó que cocinaban la cerámica en hornos, no en el suelo, que allí tenían cierta clase de arcilla especial para hacerla, y que también había chircales en la misma vereda donde empleaban greda semejante para hacer ladrillos. Mas cuando en agosto de 1970 regresé a Chocontá para buscar aquellos alfareros, encontré alguna dificultad en establecer su existencia. Primero, a todos los que pregunté en el pueblo y en la vereda, negaron que alguien hiciera cosas de barro, salvo una pareja de campesinos ancianos que me contestaron que "eso era más antes". Finalmente, me encontré con un señor que me dijo que algunos de sus parientes eran "lozeros" pero que dejaron de trabajar seis años antes. Se llamaron Simona y Alejandro Rodríguez, Susana y Feliza Forero, y Constantín Fernández. Sería interesante saber si los Forero sean emparentados con don Benjamín Forero de Chiquinquirá, quien dijo tener parientes en Chocontá. Mi informante me dijo que empleaban un torno hecho de madera, que se movía con los pies; que cocinaban en horno; y que ahora no trabajan "porque no se consigue el frailejón", pero no me dijo para qué se necesitara tal elemento. Puesto que me informó que los mencionados vivían a una hora de camino de donde estábamos, estaba lloviendo, y yo no disponía de mucho tiempo, no fuí a visitarles.

La cerámica que compré en 1960 pareció mucho a la de Tausa y Chiquinquirá. La matera tenía la forma de una copa de basa anular, con paredes algo convexas, de las dimensiones siguientes: altura, $7.5 \mathrm{~cm}$; diámetro del borde, $12.8 \mathrm{~cm}$; diámetro máximo, $13.5 \mathrm{~cm} ., 1.5 \mathrm{~cm}$. por debajo del borde; diámetro exterior de la base anular, $6.9 \mathrm{~cm}$. El platillo era de forma semejante pero más abierta; tenía $5.3 \mathrm{~cm}$. de altura, $15 \mathrm{~cm}$. de diámetro al borde, y $6.8 \mathrm{~cm}$. de diámetro exterior de la base anular. La pasta era de color crema, textura fina, algo laminar, dura; contenía partículas finas y escasas de cuarzo y un mineral rojo oscuro, y burbujas lenticulares. La superficie éra de color crema anaranjada, más o menos lisa, con estriaciones visibles resultado del empleo del torno. Ambas piezas llevaban un vidriado delgado de color entre verde y marrón oscuro, sobre el interior por lo menos. El platillo también tenía por dentro un dibujo de dos líneas incisas onduladas.

Otro lugar en el antiguo territorio Chibcha donde se hace cerámica es Nemocón, donde hay por los menos dos alfareros dedicados principalmente a hacer las gigantescas vasijas llamadas "moyas" que allá emplean para la preparación de la sal según los métodos antiguos. La señora Marianne Cardale de Schrimpff ha recogido muchos datos sobre este proceso, inclusive la fabricación de las vasijas, los cuales se espera publicar en un futuro no muy lejano. Igualmente, debe mencionarse la película documental "Hombre de la Sal", hecha por Gabriela Samper; y la señora Diane Whitlin también ha 
hecho estudios fotográficos del proceso. No obstante, hasta ahora no se dispone de ninguna descripción de las técnicas de alfarería empleadas en Nemocón para comparación con las de otros lugares, por lo cual quisiera presentar aquí los pocos datos que yo pude recoger en una visita breve, aunque se espera sean remplazados en poco tiempo por descripciones más amplias.

El 7 de agosto de 1971, hablé con don Francisco Cobo en la fábrica de sal donde trabaja en Nemocón. Siendo éste el día de festejar la batalla de Boyacá, no estaba trabajando, pero muy amablemente nos explicó a mí y dos acompañantes como lo hacía. No emplea el torno, sino el sistema de modelar con planchas de arcilla. La arcilla proviene del cerro arriba del taller, y es de color muy rojo, prácticamente igual a como sale después de cocinarse. Se muele y se mezcla con agua en un pozo con un trapiche movido por burros. No se la agrega nada de desgrasante a la greda; las pocas piedritas que se encuentran en sus productos son accidentales. Yo había pensado que debía emplear desgrasante de tiestos triturados, de ver algunos ejemplos de cerámica hecha en Nemocón, pero una inspección más o menos cuidadosa de lo que había en la fábrica me convenció de que el señor Cobo no lo utiliza. Podría ser que las vasijas que yo había visto fueran de otro fabricante, o que estaba equivocada. La manera de formar las vasijas es: se preparan planchas de arcilla de unos dos centímetros de grueso, $30 \mathrm{~cm}$. de ancho y de largo según lo que se quiere hacer. Sobre una plancha de base, se erigen otras para formar las paredes, agregando otras encima de éstas hasta llegar a la altura deseada, la cual en el caso de las moyas es alrededor de $1.80 \mathrm{mts}$. Para los que conocen las dificultades del manejo de arcilla, es realmente asombrosa su habilidad en hacer de esta manera vasijas tan grandes. Además de lo problemático de elevar en material plástico paredes tan delgadas en relación con su altura, hay que considerar los problemas de trasladarlas al horno después de secarse, de mantener temperaturas estables en el horno para que las vasijas se cocinen sin agrietarse, y su trasnporte después de cocinar, siendo pesadas, de bulto muy incómodo, y fácilmente rompibles.

Fuera de las moyas, el señor Cobo hace materas y algunas figuras y "juguetes", por ejemplo miniaturas muy atractivas de los hornos para cocinar la sal. En la misma fábrica, también hacen ladrillos, teja, y tuberías para alcantarillado. Las vasijas se dejan secar quince días; se cocinan ocho días; duran otra semana en el horno enfriándose entonces se demora ocho días más en el descargamiento del horno. Es decir, después de formarse en arcilla plástica se necesitan aproximadamente cinco semanas para terminar la cerámica. Los hornos, donde también se cocinan ladrillos, son muy grandes y mucho más complicados en comparación con los que hemos mencionado hasta ahora. Se calientan con carbón mineral, usando 10 toneladas por horneada, alimentándose, el fuego por medio de 4 o 6 bocas distintas. Un horno que tenía el techo dañado empleaba un sistema muy sofisticado de dirigir hacía abajo las corrientes de aire caliente. Este horno se había empleado para cocinar tuberías para alcantarillado con vidriado de sal; éste es el único caso de envidriar con sal que he encontrado en estas averiguaciones. Preguntando sobre ello en Tausa y Ráquira, me dijeron haberlo ensayado sin dar resultado. En Nemocón, nos dijo don Francisco que echan un bulto de sal al horno cuando el fuego ya está apagándose, para lograr el característico esmalte delgado de las tuberías. Fuera de eso, en Nemocón no emplean ningún vidriado en su cerámica; ni tampoco la pintan.

En 1970, tuve la oportunidad de visitar dos lugares de Santander donde hay unas pocas personas que hacen cerámica: Guane y el Socorro. Aunque queda fuera de la zona de los Chibchas propiamente dichos, resultó muy interesante por comparación, y 236 por lo que agrega a la variedad de las técnicas de la fabricación de cerámica sin torno. Aquí también, cabe notar que otros tienen datos mas completos que los que presento ahora. Los integrantes del grupo arqueológico encabezado por Warwick Bray, quiene me invitaron a visitar su lugar de trabajo, hicieron un estudio de los alfareros sobrevivientes para comparación con la cerámica encontrada arqueológicamente.

Cerca al pueblo de Guane, hablé con la señora Rosa Valbuena; en Socorro, con doña María Antonia Castro Robles. Puesto que hacen cerámica muy parecida, voy a describir sus técnicas juntas. Las formas que hacen incluyen ollas grandes de cuerpo redondo, cuello corto y estrecho, boca abierta, con una asa, llamadas "botijas" o "moyas"; "chocolateras" de semejante forma, pero con cuerpo de menos bulto; platos con una asa al borde para cocinar arepas, llamados "tejos"; cuencos más o menos hemiesféricos con dos asas al borde, "cacerolas" o "pailas"; y ollas de forma redondeada, pequeño borde vertical, y dos asas horizontales. La arcilla, obtenida de "minas" en las cercanías, se mezcla con piedra triturada. Este mineral es de una clase especial, de color gris y textura algo cristalina; se quema en el fuego antes de romperse y triturarse con mano y piedra de moler. La arcilla se prepara en pequeñas cantidades, suficiente para una o dos vasijas. Para hacer una vasija, sea esta olla o paila, se empieza como lo hacen en Ubaté, modelando un cuenco burdo con un pedazo de arcilla. Este se lo coloca sobre un "molde", es decir un plato de cerámica parecido a los "tejos", el cual funciona como el platillo que se utiliza en Ráquira, para facilitar alcance a todos los lados de la vasija dándole vueltas. Tal como en Ráquira, no sirve de torno verdadero para hacer subir las paredes de la vasija por medio de la fuerza centrífuga. En cambio, se emplea el sistema "coil" para ampliar la vasija. Pero es de notarse que este se hace de una manera distinta a la que se emplea en Ubaté. Las "salchichas" de arcilla no se hacen tan largas, sino únicamente de unos $15 \mathrm{~cm}$. de largo, y en vez de pegarse por encima del borde de la parte ya formada, se aplica un poco por debajo del borde a la superficie exterior o interior, según convenga. Dándole vueltas en el sentido del reloj a la vasija, las adiciones de greda se trabajan con los dedos para unirse bien con la parte de abajo, igualar el grosor de la pared, y hacerla más alta hasta llegar al tamaño deseado. Me interesó mucho ver tal variante del sistema "coil", porque podría explicar una característica que yo había notado en ciertos tipos de cerámica arqueológicos, es decir, una textura algo laminar en un sentido diagonal con referencia a las superficies. Igualmente, la manera de pegar las asas horizontales en las ollas recuerda hallazgos arqueológicos de la zona Chibcha. No se las pegan directamente a la superficie, sino se hace un hueco en la pared para insertar un terminal del asa, alisándolo y reuniéndolo a la superficie interna de la vasija, y después agregando un anillo de arcilla a cada extremo de la asa en el exterior, el cual también se alisa, para reforzar los extremos de la asa. Es decir, cada extremo de la asa atraviesa el grosor de la pared, quedando como remachado por ambos lados.

No se pinta la cerámica, ni se le decora de ninguna manera. No se la pule ni se la aplica vidriado ni baño, salvo que trabajando siempre con las manos mojadas se liquifica una delgada capa superficial para formar algo de "self-slip", tal como en Ráquira. La fabricante mantiene a su lado una olla llena de agua en donde meter la mano con frecuencia mientras trabaja.

Después de secarse, la cerámica se cocina "en el suelo", en fuego abierto y no en horno. El combustible es leña. Según la señora Castro, primero las vasijas se ponen a "caldear" en un fuego pequeño, unos dos minutos, del cual salen ahumados; después se cocinan en otra fogata más grande, unos 3 minutos, con leña bien seca y un "abrigo 
verde" de hierbas por encima. La señora Valbuena dijo que se construye una fogata de leña por encima de unas seis vasijas, las cuales se cocinan alrededor de una hora, o diez minutos por vasija. Quejándose de la mala calidad de la cerámica que hacen sus competidoras en el Socorro, aseveró que allá cocinan "con paja" (en realidad, las socorreñas emplean leña también).Es de notarse el corto tiempo de cocción mencionado por estas señoras. Aunque obviamente no se puede confiar en absoluto en aproximaciones de unos pocos minutos hechas por personas quienes probablemente carezcan de relojes, el orden de magnitud sí es confiable, y hay una gran diferencia entre una hora y las 24 horas o más mencionadas en otros lugares. La cerámica que resulta parece atestiguar una cocción o temperatura baja, apenas adecuada para lograr la metamorfosis de la arcilla. La oxidación de la pasta resulta muy incompleta; hacia afuera puede haber una capa de color entre carmelita y rosado, pero por dentro es de color gris oscuro. La textura es burda y porosa, con mucho desgrasante, y la dureza es aproximadamente 3 en la escala de Mohs, mientras que las cerámicas de Ubaté, Ráquira y Nemocón alcanzan una dureza de 4 o 5, de la misma escala (1= Talco, 10=diamante).

\section{Conclusiones}

Pese a la naturaleza casi rudimentaria de las investigaciones resumidas arriba, de ellas es posible sacar algunas conclusiones. No puede restarse a Ráquira su importancia primordial como centro de producción de la cerámica de uso general entre los campesinos modernos de la altiplanicie Cundiboyacense, pero queda en claro que hay otros lugares donde existe una industria casera de alfarería. Además de los mencionados aquí, me han informado de otros lugares que no he podido visitar hasta ahora, por ejemplo La Capilla, del municipio de Tenza; las veredas Sopotá y El Espinal de Villa de Leiva; Morcá y Tutasá. También, por supuesto hay el conocido e importante centro ceramista de La Chamba, cerca a Girardot. Aunque queda fuera del territorio de mis investigaciones, sus productos fácilmente reconocibles de cerámica pulida roja o negra llegan a muchos mercados pueblerinos de la Sabana de Bogotá.

Las tradiciones ceramistas obviamente caen en dos grupos: las de procedenci claramente europea, y las que parecen arraigarse más bien en tradiciones indígenas, aunque aún éstas manifiestan algunas influencias foráneas, como sería de esperarse cuatro siglos y medio después de la Conquista. Las características distintivas de la cerámica hecha en Tausa, Chiquinquirá, el centro urbano de Ráquira, y la que antes se hacía en Chocontá, son netamente de origen europeo, sobre todo por el empleo del torno y el vidriado. La carencia de material desgrasante agregado a la arcilla probablemente sigue al uso del torno, porque la presencia de partículas duras y ásperas maltrataría a las manos del alfarero debido a la rapidez de movimiento de la masa de arcilla en el torno. El cocinar en hornos de forma de colmena también parece forma parte de esta tradición importada; aunque los hornos no son exclusivos de estos lugares, es la única manera de cocinar que en ellos se emplea, además de ser la manera de hacerlo en Europa. Su semejanza de forma al horno de cocinar el pan de trigo también es sugestiva. Las formas de las vasijas son de tradición europea: jarras con borde en pico y una asa; tasas y platillos; y materas, porque sembrar plantas en vasijas especiales de barro no parece ser una costumbre indígena. Las bases planas y de forma anular obedecen a las posibilidades del torno; bases asi son de formación relativamente fácil sobre el torno y más difícil de otra manera. Es de notarse la uniformidad de las técnicas empleadas en los distintos lugares, y del producto: arqueológicamente, sería 238 muy difícil distinguirlos. En cuanto a esta uniformidad, es interesante señalar que un ceramista en Chiquinquirá mencionó tener parientes en Chocontá, y que hay fabricantes del mismo apellido en Tausa. Cabe mencionar, también, que la importante familia ceramista de los Suárez, del pueblo de Ráquira, parece tener origen en otro lugar.

Las técnicas y productos de los lugares del segundo grupo no son tan uniformes: es decir, Ubaté, las veredas de Ráquira y la Candelaria, Nemocón, y en Santander. Lo que tienen en común es que ningunos utilizan el torno para formar vasijas, y no aplican vidriado a sus productos. La carencia de estas marcas inconfudibles de influencia europea sugiere una continuidad de tradición con la cerámica prehistórica, más bien que una introducción post-conquista. La variedad de las técnicas empleadas es muy notable. Se le agrega a la greda algún mineral desgrasante en todos los lugares, exceptuando Nemocón, pero en Santander se trata de piedra molida y en los otros es arena. La técnica "coil" se emplea en Ubaté y en Santander, pero con diferencias interesantes entre ellos. El "torno lento" se utiliza en Ráquira y en Santander, pero con sistema "coil" en el último y una forma de modelaje directo en el primero. La cerámica se cocina en fuego abierto en Ubaté, en Santander, y probablemente en Ráquira también, pero en Nemocón emplean hornos de los más sofisticados que he visto, los cuales probablemente son por influencia de la industria europea de hacer ladrillos de barro quemado, que es otra función del mismo taller. Es de notarse también que es únicamente en Nemocón, entre estos lugares, donde se emplea algún sistema de envidriado, en este caso con sal -la cual se prepara allí mismo-y únicamente para las tuberías. Pero es netamente indígena el fin original del producto principal de su alfarería: extraer la sal del agua salada, tal como lo describen los cronistas de la época colonial.

Una diferencia muy notable es la distribución de los productos de los distintos centros: la de la cerámica campestre de Ráquira es mucho más amplia que los demás. Aquella se consigue en todos los mercados semanales de los pueblos del altiplano: hasta ahora, no he visto ningún mercado, allá, donde no haya un puesto de vender cerámica de Ráquira. Se ve en hogares campesinos por toda la zona, y tiestos de tal cerámica se encuentran por todos lados desde Facatativá hasta Sogamoso y Villa de Leiva por lo menos. En cambio, la de Ubaté, no la he notado para la venta sino en el mercado del mismo pueblo, y las vasijas no las he visto en casas campesinas más lejos que Tausa. Fuera de la cerámica raquireña, la distribución de las demás parece ser muy local, exceptuando unas cuantas piezas que llegan a ser compradas por coleccionistas o vendedores de artesanías de la capital.

La variedad de los sistemas de fabricación entre estos centros no es muy sorprendente desde un punto de vista arqueológico, porque en la cerámica prehistórica también hay una gran variedad de tipos, muchos según parece más o menos contemporáneos. Cabe mencionar que sería muy fácil reconocer como tipos distintos cerámica de los centros bajo consideración encontrada arqueológicamente. En realidad, es posible sugerir algunas relaciones entre estos tipos y algunos conocidos arqueológicamente. La cerámica de Ubaté y de las veredas de Ráquira podría considerarse como descendiente de un grupo de tipos que he denominado Tunjuelo Arenoso, Funza Laminar Duro, y Choconta Arenoso Grueso, entre otros. Aunque sí se han encontrado en la zona más al sur del territorio Chibcha, como lo indican los apelativos que he escogido para los dos primeros, parecen ser más comunes hacia el norte, es decir desde Chocontá y la zona limítrofe entre los departamentos de 
Cundinamarca y Boyacá, o sea más o menos la misma zona de Ubaté y Ráquira. La cerámica de Nemocón podría relacionarse con el tipo Guatavita Desgrasante Tiestos, subtipo Rojo Burdo, por su textura general, aunque carece del desgrasante característico del tipo arqueológico. En Santander, según los integrantes del equipo de Bray, hay algunas semejanzas entre la cerámica prehistórica más reciente y la del Socorro y Guane. Debemos considerar que carecemos en absoluto de información sobre los antecedentes inmediatos de los tipos modernos y su duración temporal, ya que los arqueólogos no nos hemos preocupado por la época colonial, la cual constituye un hueco de tres o cuatro siglos en las secuencias culturales. No sabemos qué tanto tiempo atrás se han hecho los tipos modernos, ni qué tanto después de la conquista se hacían los prehistóricos.

Emprendí este modesto estudio con el fin de complementar mis investigaciones arqueológicas en el territorio Chibcha. Desde el punto de vista de la interpretación de la cerámica prehistórica, aprendí unas cosas para mí interesantes. La misma variedad de técnicas y sistemas de elaborar la cerámica, anotada arriba, es de mucho interés: hace pensar que las diferencias entre los tipos arqueológicos deben resultar de semejante variedad de técnicas. El sistema "coil" no es la única posibilidad en la ausencia del torno verdadero, y resulta que hay más de una forma para hacer el mismo sistema "coil", que afectarán la textura y las maneras y líneas de facturarse la pasta. Debe recordarse que no se sabe si el "torno lento" existía en el Nuevo Mundo antes de la llegada de los europeos o si es de introducción posterior. Unos detalles de la fabricación ayudan al entendimiento de semejantes detalles en la cerámica antigua, por ejemplo la formación de las asas por medio de estirarlas con la mano mojada, y las maneras de pegarlas después de formadas, El borde de sección angular característico de las ollas de Ráquira resulta de la manera de operar con una piedra. Es de mucho interés saber que lo que parece un baño de la misma greda como la pasta puede resultar de trabajarla con las manos mojadas, liquificando así una capa superficial de la misma pasta. Tal vez lo más significativo, desde el punto de vista de la tipología arqueológica, es el hecho de la adición a propósito de materiales desgrasantes a la arcilla. Muchas veces es difícil saber si se trata de deliberadas adiciones o inclusiones fortuitas en la cerámica arqueológica. Pero en Ubaté, Ráquira y Santander, es cuestión de agregar arena seleccionada o piedra triturada cuidadosamente preparada a una arena escogida por su pureza, resultando en una pasta que lleva inclusiones en bastante cantidad, mientras que en la cerámica de Nemocón, y en la hecha en torno, las inclusiones son escasas. Puesto que, para la cerámica prehistórica, son las diferencias del desgrasante las que han resultado más útiles para diferenciar los distintos tipos, es muy alentador para el arqueólogo tipologista tener tal confirmación de la significación cultural del empleo del desgrasante. También es interesante tener confirmación de testimonio directo visual y de dicho de los mismos fabricantes de algunas conclusiones logradas por el examen de tiestos y piezas compradas en el mercado, tales como la manera de hacer la textura superficial tan característica de la cerámica de las veredas de Ráquira, su pauta intencional y la de los dibujos burdos formados por la pintura aplicada con un trapo y que no son nada accidentales, sino el resultado de ciertos hábitos, modalidades, y concepciones culturalmente determinados.

Obviamente, se necesitan estudios mucho más profundos que los que resumo aquí, de todos los lugares mencionados y otros también. Sería valioso seguir más a fondo los detalles de la tecnología ceramista, y tratar de averiguar algo sobre su historia y sus relaciones con las tradiciones prehistóricas y europeas, y las invenciones recientes en la misma zona. La economia de la alfarería tradicional tambien sería interesante: la producción semanal de un fabricante, los precios recibidos, la proporción que contribuye a los ingresos familiares; la distribución del producto, si por intermediarios o personalmente, a qué distancia, a quienes se vende y para qué lo compran. $\mathrm{La}$ estructura social, por supuesto, debe formar parte de tales estudios, en especial las conexiones familiares entre ceramistas en un solo lugar y en distintos pueblos. Otro asunto que sería interesante estudiar, aunque no muy fácil, sería el de los valores y conceptos relativos a su trabajo que tengan los alfareros: qué es lo que tratan de hacer en su cerámica, qué características les parecen deseables en la cerámica, si hay algún motivo consciente para hacer tal y cuál detalle de tal manera, qué clases de materiales crudos y vasijas terminadas reconocen, qué tanto variables son las clases, para qué fines hacen sus productos, etc. Como he dicho antes, en varios casos se puede esperar más información de investigaciones ya hechas. La localización de los centros y su limitada distribución es otra pregunta: a veces se dice que es porque en aquellos lugares hay arcilla aprovechable, pero por lo general parecen ser las arcillas finas del lecho de los lagos pleistocénicos las que se prefieren para la cerámica, y éstas hay en muchos otros lugares.

Para terminar, quisiera expresar unos conceptos personales sobre los ceramistas que tuve el placer de conocer y sus obras. Sin excepción alguna, me recibieron con suma cordialidad, gentileza y cortesía, y la generosa hospitalidad que siempre he encontrado entre la gente campesina de Cundinamarca y Boyacá. Contestaron mis preguntas con afabilidad, inteligencia e interés; con pocas explicaciones, se entendieron de lo que yo quería, e hicieron esfuerzos especiales para mostrarme todos los procesos posibles, con cierto orgullo modesto y más que justificable en su destreza para hacer objetos útiles y gratos a la vista del mero barro. A todos, debo una gratitud muy sincera y profundamente sentida, y además una admiración por su habilidad, talento y buen gusto artístico.

Por lo general, yo siempre he tratado de limitarme en la expresión de opiniones personales o evaluaciones de lo que he visto en Colombia, por consideracione antropológicas de la relatividad cultural además de las de la simple cortesía debida a un país donde uno está de visitante. Si me aparto un poco de tal costumbre en la presente ocasión, espero que me perdonen. He sentido cierta inquietud en cuanto a algunos de los ensayos bien intencionados por parte de entidades tanto extranjeras como nacionales de ofrecerles ayuda y estímulo hacia el "progreso" a los ceramistas artesanales; he notado inquietudes semejantes expresadas en la prensa diaria también Me parece que existe una tendencia a tratar a los artesanos demasiado como industriales subdesarrollados y no suficientemente como artistas maduros. Sus productos han encontrado una venta considerable en un mercado turístico, el cual ha aumentado rápidamente en los últimos años según parece por el incremento numeroso de almacenes dedicados a la venta de esta clase de mercancías. Dada la demanda, es natural pensar en fomentar un incremento en el abastecimiento, es decir tratar de aumentar la producción. Pero si sus productos merecen admiración por sus cualidades artísticas, las cuales son innegables y han originado tal demanda, hay que considerar que dichas calidades, en gran parte, podrían ser el resultado de los mismos factores que limitan la producción, es decir las técnicas "primitivas". Cuando a las artesanías se les aplican sistemas industriales de producción, encaminados hacia la estandarización de los productos, dejan de ser artesanías para convertirse en productos industriales. Por lo general, es notoriamente difícil aumentar mucho la producción de un artista sin dañar 
su calidad. A fin de cuentas, a un artista de categoría uno no le insinúa cómo aumentar sus ingresos al producir en mayor cantidad: uno le paga lo que vale su obra Y los alfareros sí son artistas, algunos de categoría bastante alta, por la destreza que los años de experiencia y práctica han dado a sus manos, por su imaginación fértil y humorística, por su buen ojo para las formas y texturas, y por la buena adaptación de sus productos a sus fines esenciales. Porque es de considerarse, tạmbién, que aunque sus productos resulten al gusto de turistas y decoradores de interiores, y que los ceramistas estén dispuestos a hacer lo que se puede vender, no importa quién sea el cliente, las artesanías no se desarrollaron para fines turísticos sino para llenar ciertas necesidades de la vida campesina. Tales necesidades todavía subsisten, y al fin y al cabo tal vez sería más importante que el campesino pobre pudiera comprar una olla barata y práctica, de la cual los fríjoles salen sabrosos, que el turista lleve tal cual objeto féo e inútil, inscrito "Recuerdo de Colombia".

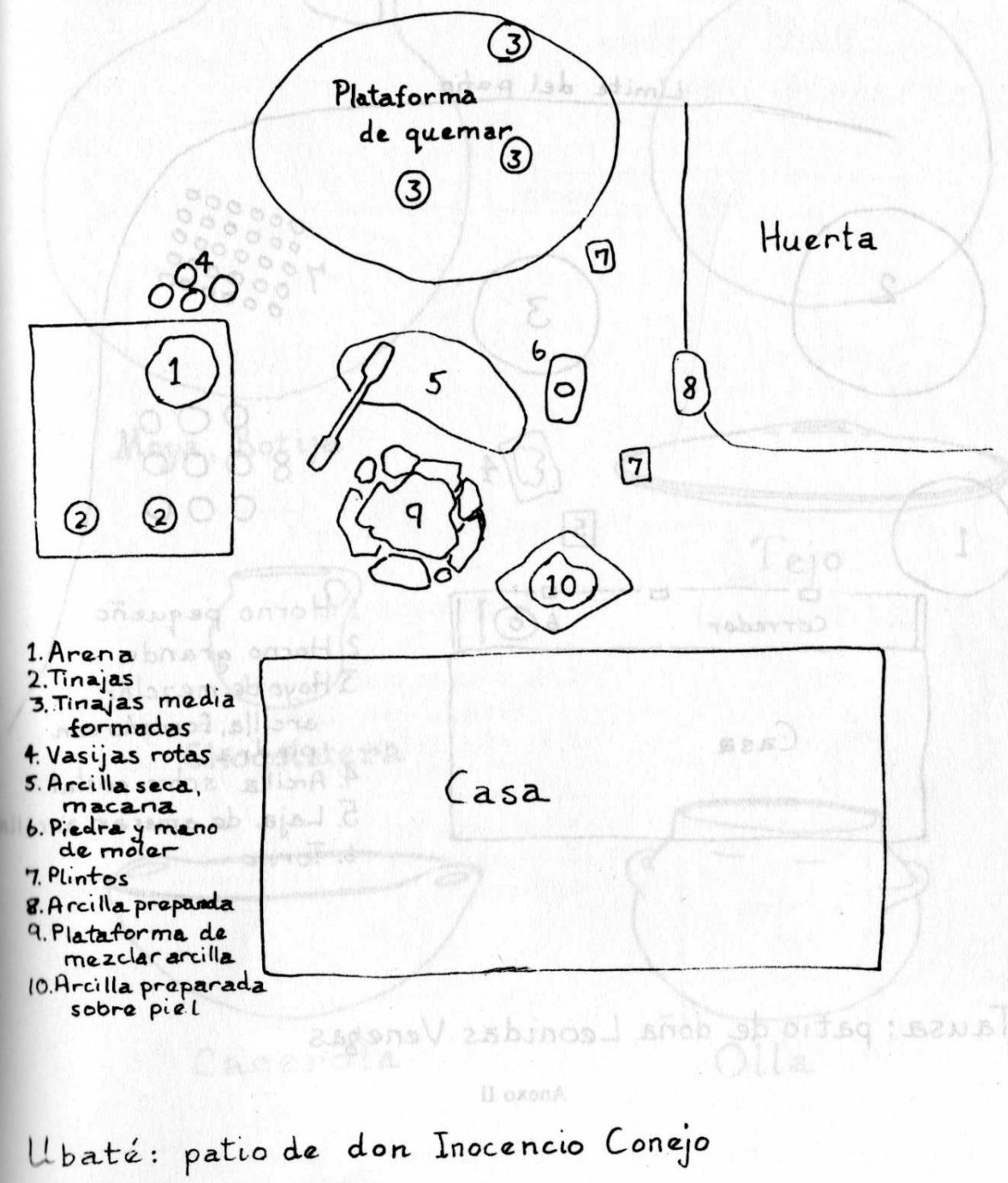

Anexo I 


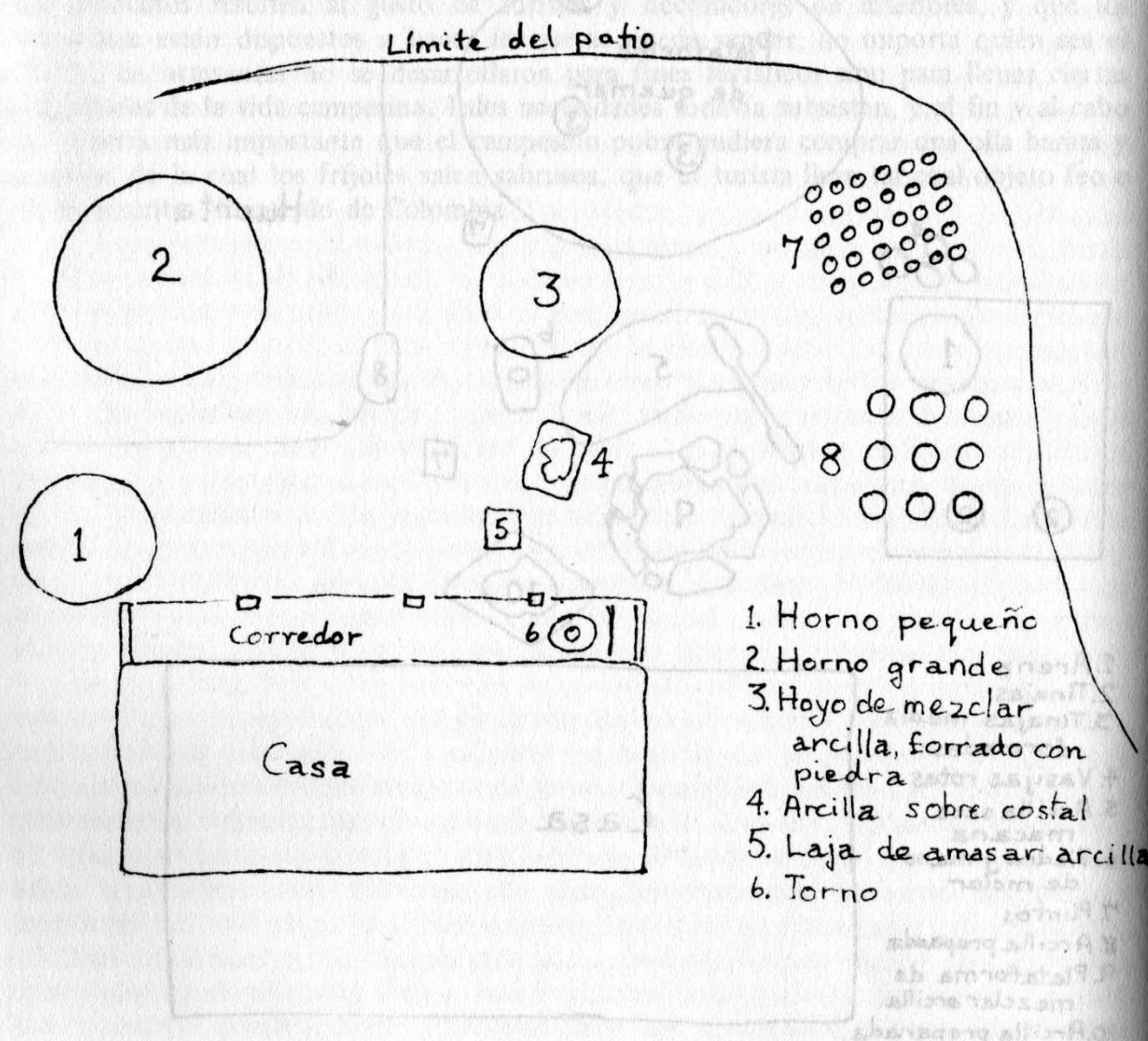

Tausa: patio de doña Leonidas Venegas

Anexo II
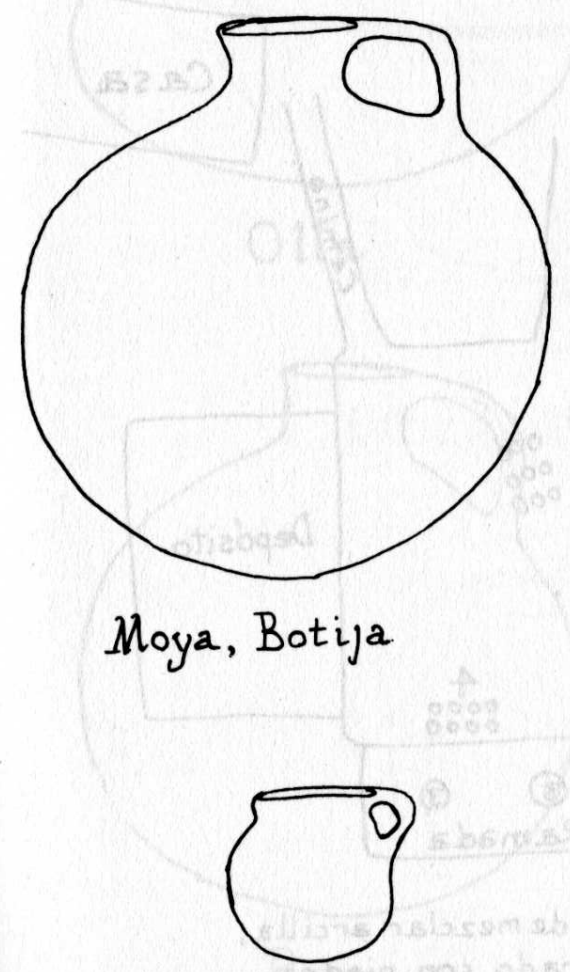

\section{Chocolatera}

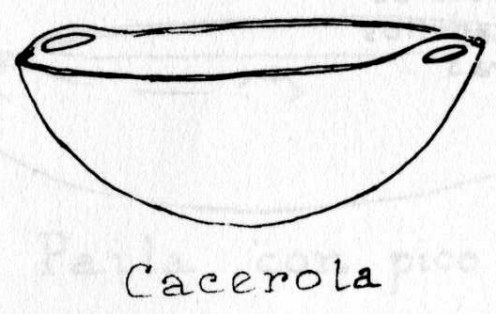

Santander: formas de vasijas
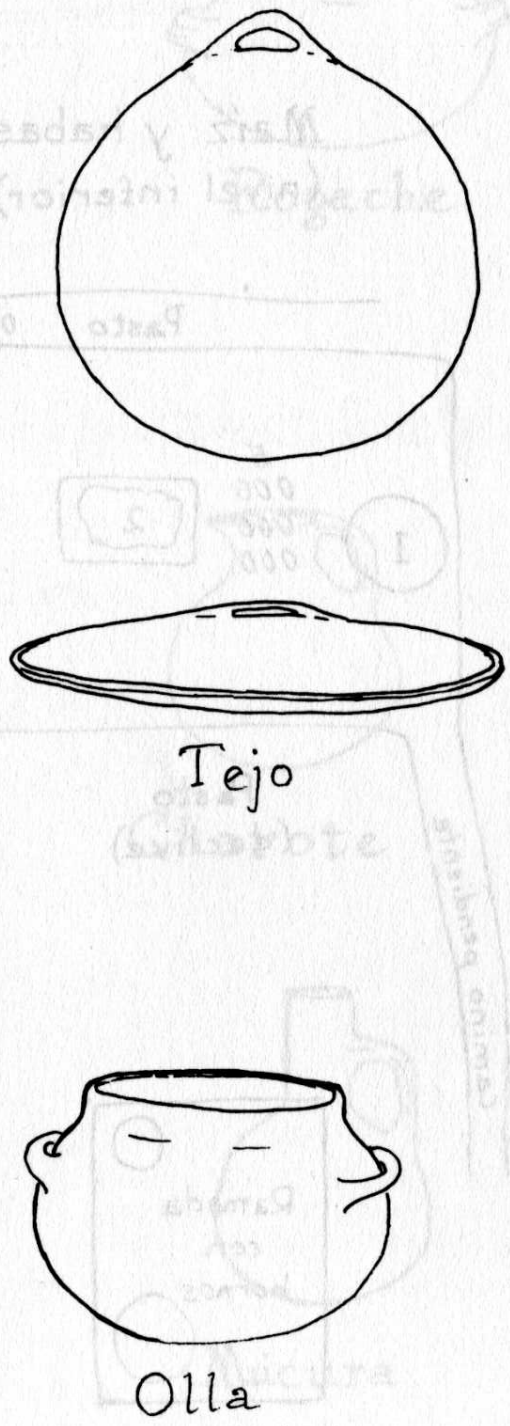

Anexo III 

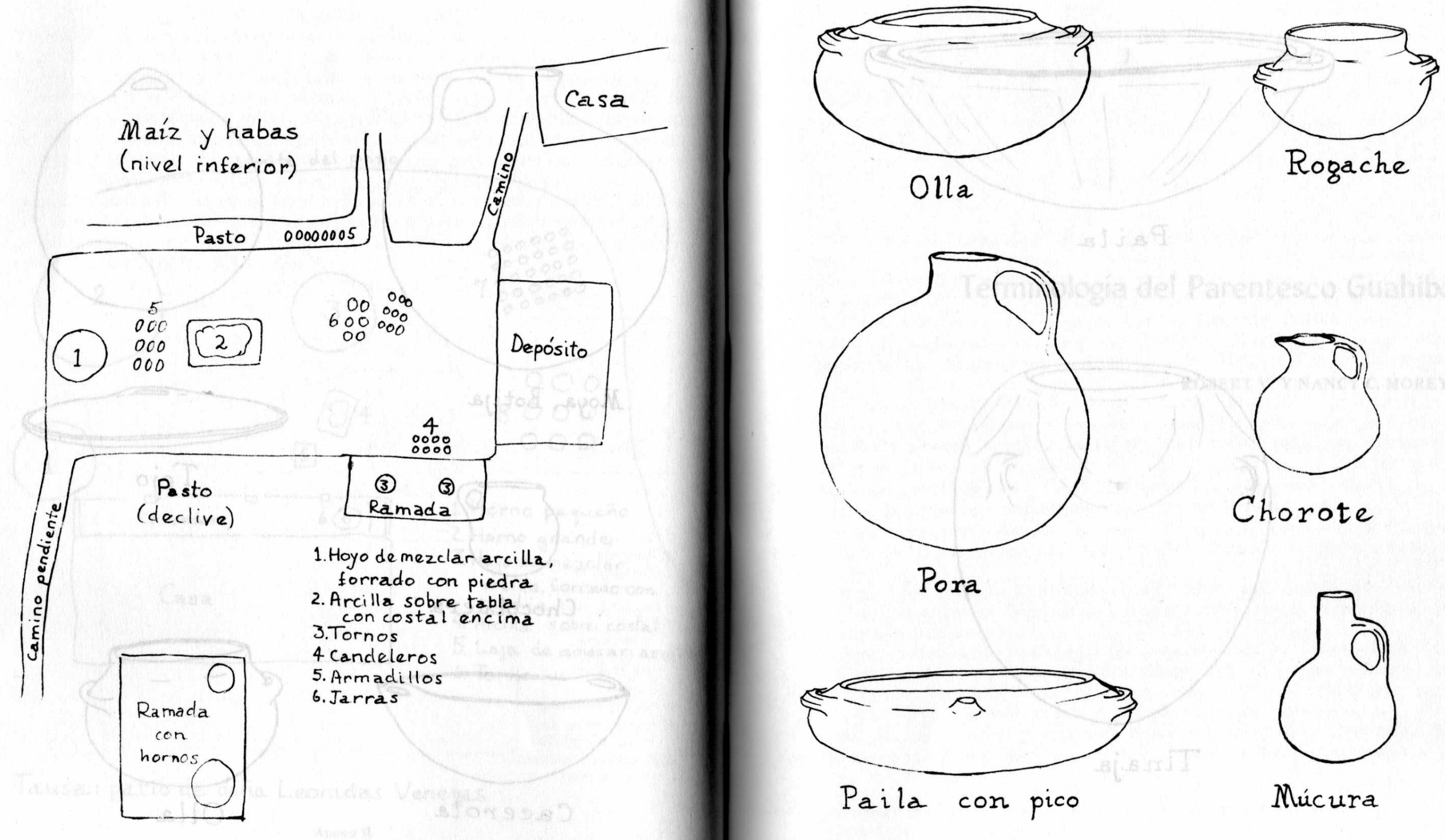

Chiquinquirá: patio de don Berjamin Forero Anexo IV

Ráquira: Formas de vasijas

Anexo V 

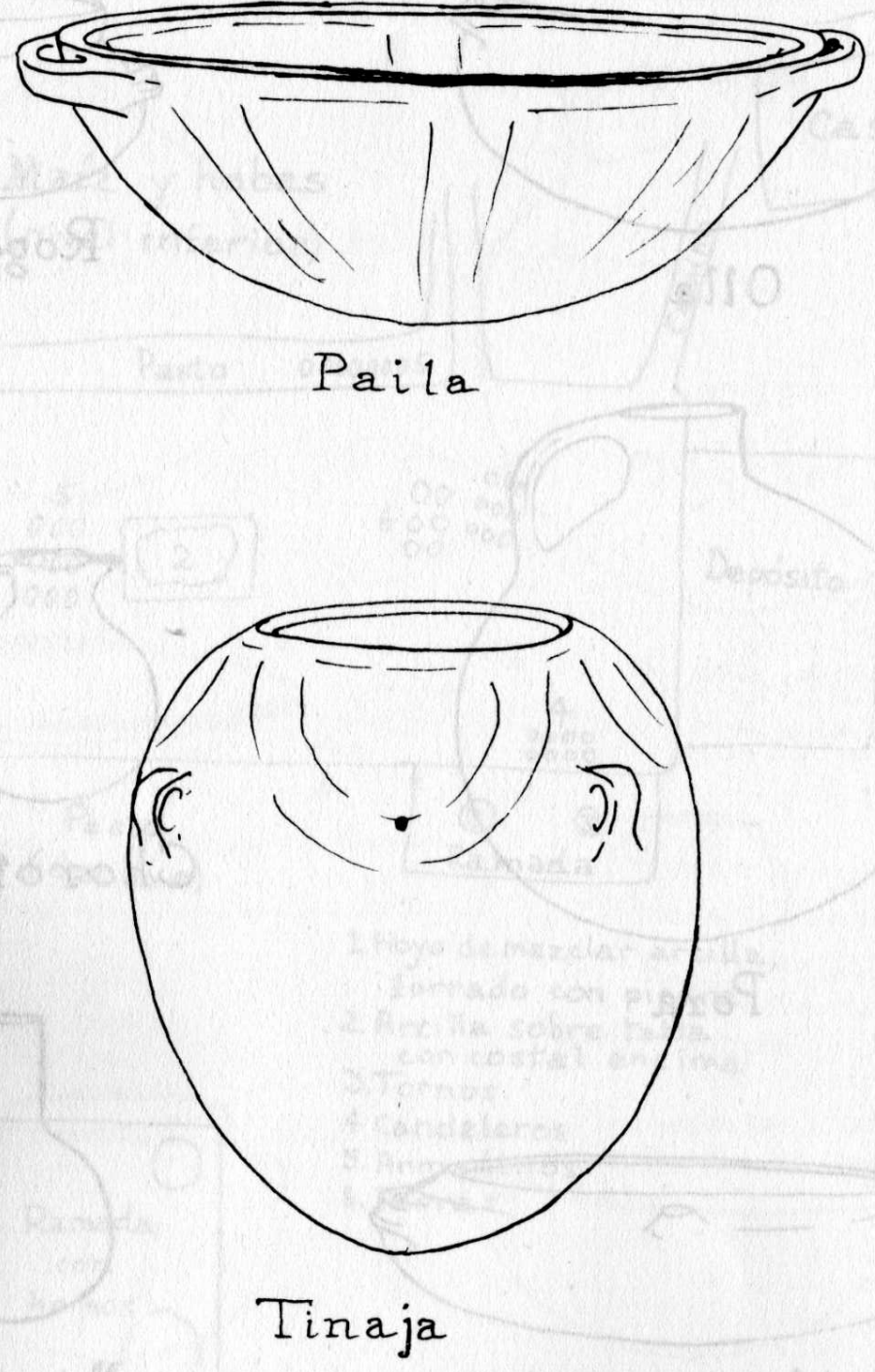

Ubaté: formas de vasijas 